\title{
THE GooseMan: A simulator for transhiatal esophagectomy
}

\author{
Kanika Trehan, MS, ${ }^{a}$ Xun Zhou, BS, ${ }^{a}$ Yufei Tang, BS, ${ }^{\mathrm{a}}$ Doru Petrisor, PhD, ${ }^{\mathrm{b}}$ Clinton D. Kemp, MD, ${ }^{\mathrm{a}}$ and \\ Stephen C. Yang, MD ${ }^{\mathrm{a}}$
}

Esophageal cancer is the fastest growing cancer in the United States and the seventh leading cause of cancerrelated death worldwide. ${ }^{1,2}$ The gold standard therapy is surgical resection commonly performed as a transhiatal esophagectomy (THE), which involves blindly dissecting the esophagus in the mediastinum through abdominal and cervical neck incisions. ${ }^{3,4}$ Compared with transthoracic esophagectomy, which requires creating a direct thoracic incision, THE has similar long-term survival but is less invasive and has fewer complications, a shorter recovery time, and decreased in-hospital mortality. ${ }^{5,6}$ Yet, morbidity and mortality from THE remain high compared with other thoracic procedures, ${ }^{7-9}$ largely a result of complications that arise during the blind mobilization process, such as injury to blood vessels, pleural entry, tracheobronchial injury, and hypotension and arrhythmia from compression of the heart. ${ }^{6}$

Although THE is difficult to perform, it is also difficult to teach because limited space and lack of visualization in the mediastinum minimize opportunities for careful supervision. In addition, learning opportunities are limited because many surgeons perform transthoracic esophagectomy or laparoscopic esophagectomy instead. ${ }^{10}$ Surgical simulation may provide a safe and accessible alternative for THE training; however, there are currently no simulators that can be adapted for this operation. Thus, we developed THE GooseMan, a simple bench model for THE simulation training made of synthetic materials along with porcine organs that costs $<\$ 200$ to build. It includes a plastic torso, artificial diaphragm, large foam lungs, an artificial pressure-detecting heart, aortic and azygous circulation, and a porcine organ block. The model facilitates practice of esophageal mobilization and gastric tubularization while simulating the complications of hypotension as well as aortic and azygous bleeding.

\footnotetext{
From the Division of Thoracic Surgery, ${ }^{\mathrm{a}}$ Department of Surgery, and the Urology Robotics Laboratory, ${ }^{\text {b }}$ The Johns Hopkins Medical Institutions, Baltimore, Md.

Disclosures: Authors have nothing to disclose with regard to commercial support. Received for publication Sept 27, 2012; revisions received Jan 19, 2013; accepted for publication Feb 27, 2013.

Address for reprints: Stephen C. Yang, MD, The Johns Hopkins Medical Institutions, 600 N. Wolfe St, Blalock 240, Baltimore, MD 21287 (E-mail: syang@jhmi.edu). J Thorac Cardiovasc Surg 2013;145:1450-2

0022-5223/\$36.00

Copyright (c) 2013 by The American Association for Thoracic Surgery http://dx.doi.org/10.1016/j.jtcvs.2013.02.056
}

\begin{abstract}
MATERIALS AND METHODS
Torso

We purchased a hollow, plastic, life-size clothing mannequin and created permanent abdominal and cervical incisions, as well as a removable anterior chest wall. A piece of hard plastic tubing was screwed on to the inner back wall to represent the spine. The spine and inner back wall are covered with a layer of silicone to create a more lifelike texture, and the abdominal incision is lined with foam pipe insulation to conceal sharp edges (Figure 1).
\end{abstract}

\section{Diaphragm}

The diaphragm was created from a one-eighth-inch-thick sheet of polyurethane. A hole was cut at the location of the esophageal hiatus, and the sheet was secured between 2 polycarbonate supports using plastic screws. The entire apparatus was screwed into place above the abdominal incision, allowing for easy replacement if it is damaged with repeated use (Figure 2).

\section{Foam Lungs}

Two blocks of memory foam were sculpted roughly into the size and shape of human lungs. They were lined with plastic wrap and coated with oil spray to recreate the slippery texture of the visceral pleura. Inside the thoracic cavity, the foam lungs establish a realistic feeling of mediastinal compactness (Figure 3).

\section{Artificial Heart}

A heart was synthesized from 4 standard rubber balloons nested inside each other and filled with water to create a realistically rigid model of the appropriate size. The balloons are connected to an external pressure gauge that produces readings that vary by $75 \mathrm{~mm} \mathrm{Hg}$ in response to the typical levels of pressure imposed on the heart during intrathoracic esophageal manipulation.

\section{Biologic Tissue}

Intact porcine organ blocks including the stomach, esophagus, aorta, trachea with thyroid cartilage, mainstem bronchi, and lungs were obtained from our institutional laboratory. The organs were rinsed under tap water, and the stomach and esophagus of each block were filled with $8 \%$ ethanol and sutured closed. The blocks were then stored in $8 \%$ ethanol at $4{ }^{\circ} \mathrm{C}$; we found that this technique preserved the organs for $>2$ months without any noticeable change in appearance or texture. Before simulation, each organ block is soaked in a tub of roomtemperature water and a nasogastric tube is placed in the esophagus to help facilitate localization. The organs are then placed inside the thoracic cavity and the stomach is pushed below the diaphragm; the thyroid cartilage is secured firmly in place through an axial hole in the neck, allowing the esophagus to remain taught (Figure 2).

\section{Aortic and Azygos Circulation}

The porcine aorta, while still attached to the organ block, remains in the mediastinum posterior to the foam lungs. Hemorrhage is simulated by release of artificial blood from intravenous bags connected to pieces of tubing that run through the right foam lung and open into the mediastinum. The artificial blood is made from red and blue food coloring to simulate aortic and azygos blood, respectively. After the internal contents are situated appropriately, the anterior chest wall is secured in place and the complete 


\section{Abbreviation and Acronym}

$\mathrm{THE}=$ transhiatal esophagectomy

model is covered in surgical drapes with retractors to simulate the operating room view (Figure 4).

\section{DISCUSSION}

Our next step is to assess THE GooseMan's validity as a surgical simulator for THE. Thoracic surgeons and surgical residents will evaluate the model based on visual appearance, tactile realism, physiologic responses, and ability to improve a trainee's skill in the operating room in terms of highest pressure placed on the heart, total time of procedure, as well as response to mediastinal hemorrhage.

Ultimately, we hope to apply THE GooseMan in the setting of surgery resident training and education. The cardiothoracic surgical simulation boot camp held annually by the Thoracic Surgery Directors Association is an excellent place where

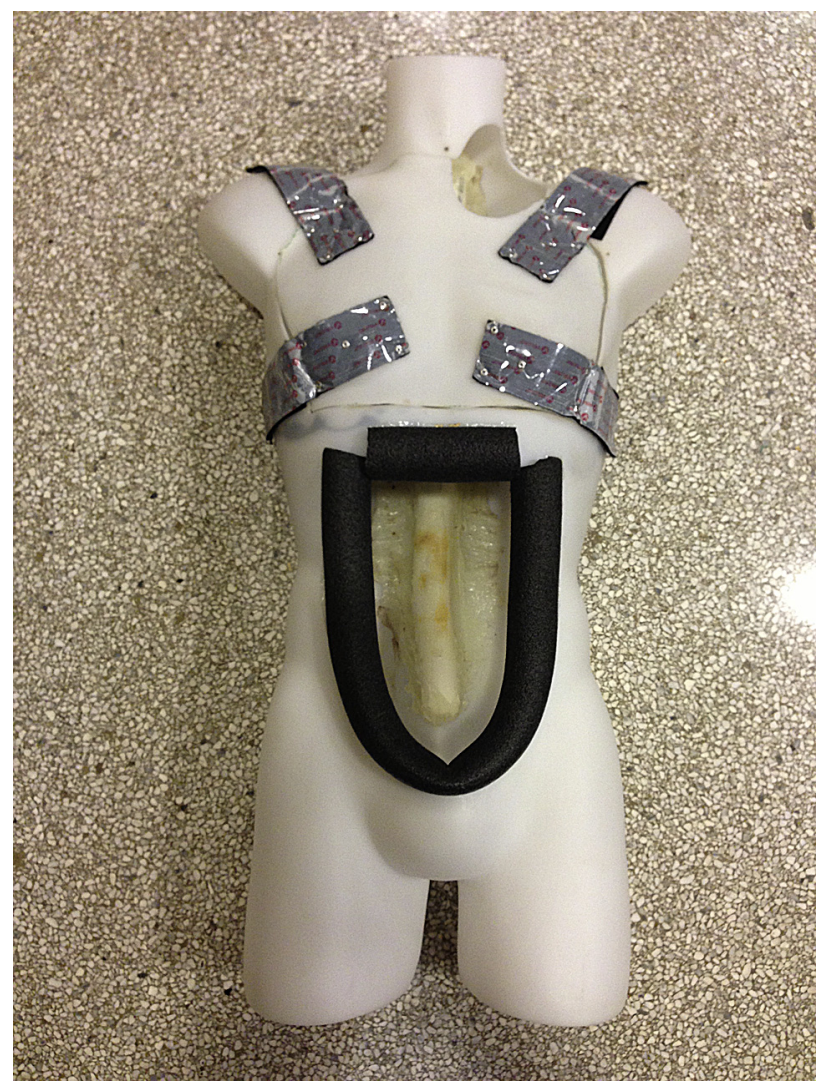

FIGURE 1. THE GooseMan is made from a plastic mannequin with abdominal and cervical neck incisions as well as a removable anterior chest wall that can be secured firmly in place using 4 large strips of Velcro. A piece of hard tubing simulates the presence of the spine, and a silicone covering helps establish a more realistic texture of the posterior wall.
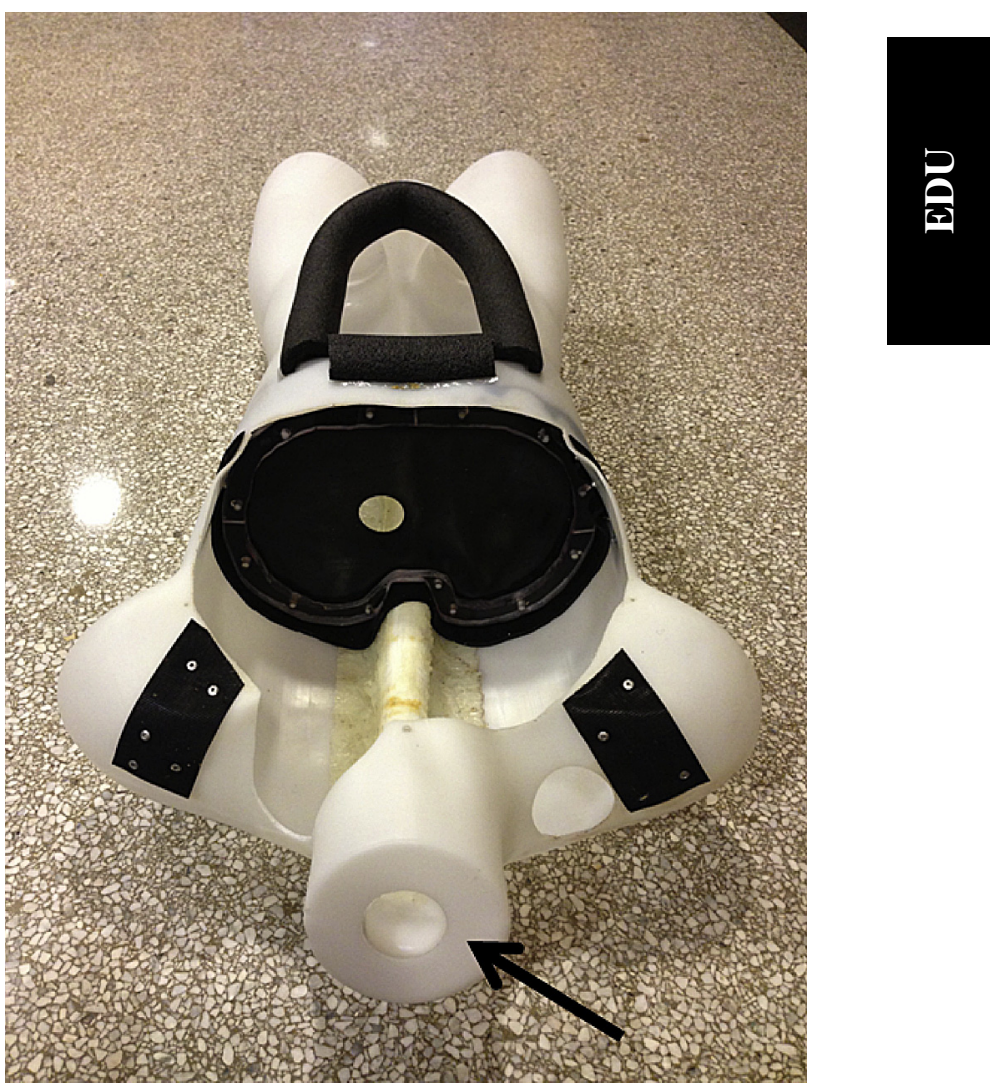

FIGURE 2. An artificial diaphragm is made from a sheet of polyurethane rubber, and a hole for the esophageal hiatus is placed in the appropriate location. An axial hole in the neck of the mannequin is used to anchor the thyroid cartilage in place (arrow).

first-year residents as well as experienced faculty can be recruited for assessment of THE GooseMan. ${ }^{11}$ In addition, we hope to use THE GooseMan in medical education by providing medical students with earlier hands-on exposure to thoracic surgery for purposes of increasing interest as well as skill level among students. Other groups have already studied the impact of surgical simulation on medical student interest, with encouraging results. ${ }^{12,13}$ Considering the declining numbers of applicants to thoracic surgery programs, this could be of great significance to the future of the field. ${ }^{14}$

\section{CONCLUSIONS}

Simulation is playing an increasingly important role in how we train surgeons because it reduces patient exposure to the risks of surgical errors. Unfortunately, our current body of thoracic surgical simulators is not adaptable to all procedures, one of the more critical ones being THE. Realizing the need for accessible, low-cost simulation for THE training, we created THE GooseMan, an inexpensive, simple bench model that facilitates practice of some of the most difficult steps of this procedure. Our next step is to assess the validity of this model to provide a safer alternative for introductory THE training. 


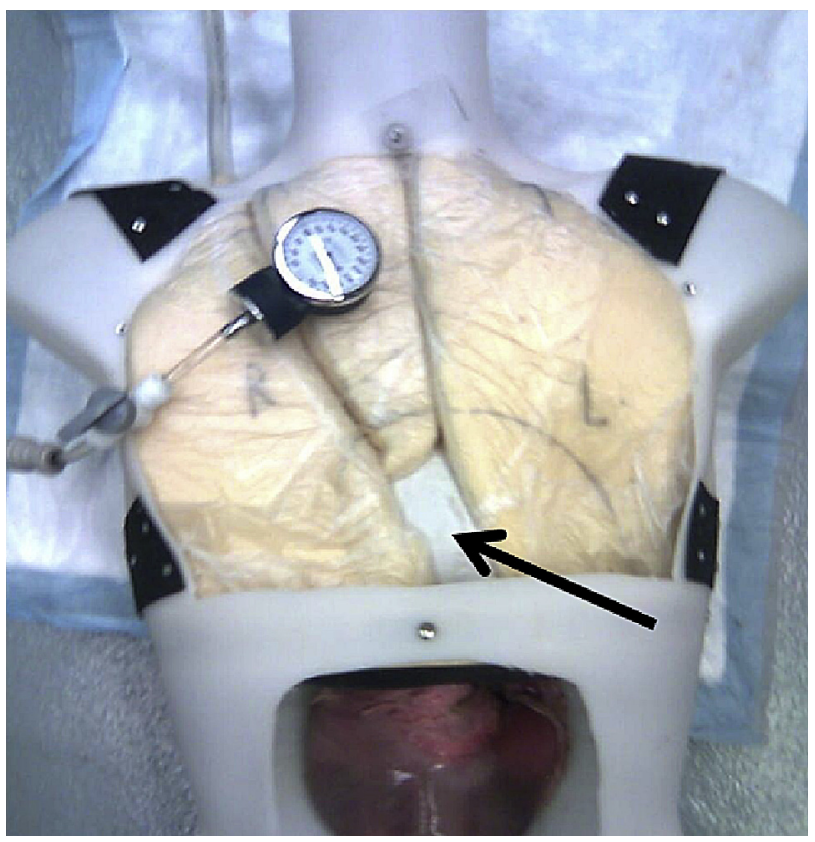

FIGURE 3. Foam lungs lined with plastic wrap and an artificial heart (arrow) are placed inside the thoracic cavity on top of the thoracic portion of the porcine organ block. The heart is connected to a blood pressure gauge via a piece of tubing.

\section{References}

1. Cohen DJ, Ajani J. An expert opinion on esophageal cancer therapy. Exp Opin Pharmacother. 2011;12:225-39.

2. Bollschweiler E, Wolfgarten E, Gutschow C, Holscher AH. Demographic variations in the rising incidence of esophageal adenocarcinoma in white males. Cancer. 2001;92:549-55.

3. Stark SP, Romberg MS, Pierce GE, Hermreck AS, Jewell WR, Moran JF, et al. Transhiatal versus transthoracic esophagectomy for adenocarcinoma of the distal esophagus and cardia. Am J Surg. 1996;172:478-81; discussion 81-2.

4. Avital S, Zundel N, Szomstein S, Rosenthal R. Laparoscopic transhiatal esophagectomy for esophageal cancer. Am J Surg. 2005;190:69-74.

5. Pertl L, Zacherl J, Mancusi G, Gachter JN, Asari R, Schoppmann S, et al. High risk of unilateral recurrent laryngeal nerve paralysis after esophagectomy using cervical anastomosis. Eur Arch Otorhinolaryngol. 2011;268:1605-10.

6. Farlo JN, Thangathurai D, Grover A, Mikhail M. Bronchial air leak during transhiatal esophagectomy. J Cardiothorac Vasc Anesth. 1999;13:723-5.

7. Low DE. Open versus minimally invasive esophagectomy: what is the best approach? Frame the issue. J Gastrointest Surg. 2011;15:1497-9.

8. Butler N, Collins S, Memon B, Memon MA. Minimally invasive oesophagectomy: current status and future direction. Surg Endosc. 2011;25:2071-83.

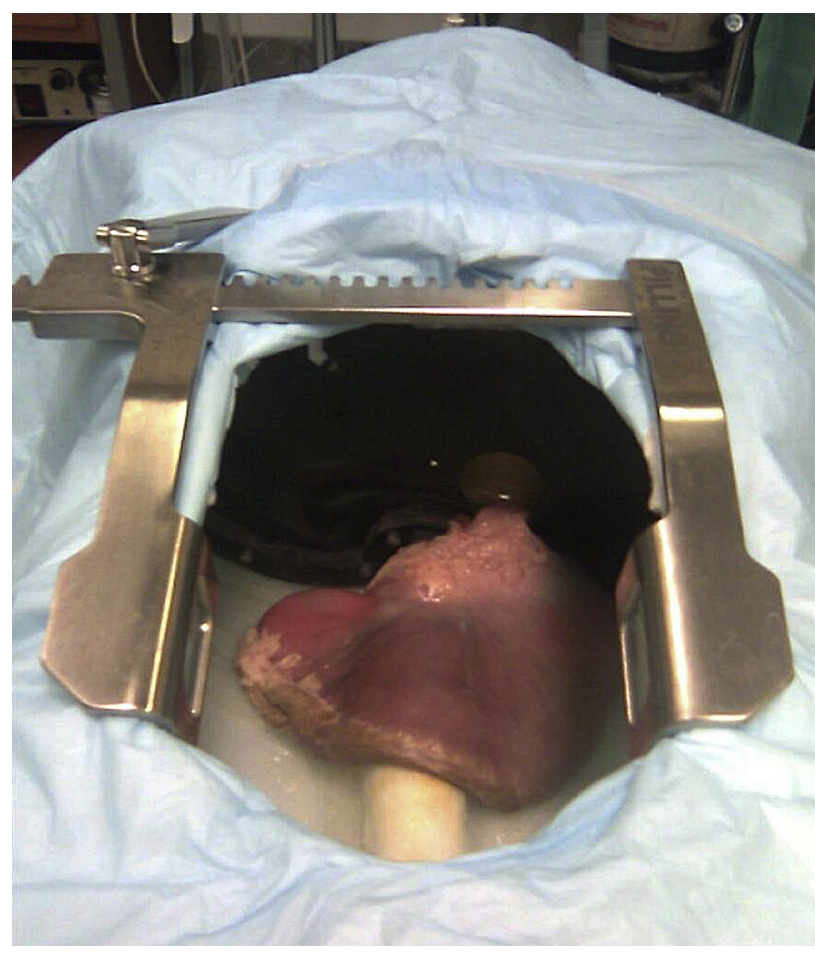

FIGURE 4. After all contents are placed inside the torso, it is covered with surgical drapes and surgical retractors to simulate a more realistic appearance of transhiatal esophagectomy.

9. Gopaldas RR, Bakaeen FG, Dao TK, Walsh GL, Swisher SG, Chu D. Videoassisted thoracoscopic versus open thoracotomy lobectomy in a cohort of 13,619 patients. Ann Thorac Surg. 2010;89:1563-70.

10. Dantoc MM, Cox MR, Eslick GD. Does minimally invasive esophagectomy (MIE) provide for comparable oncologic outcomes to open techniques? A systematic review. J Gastrointest Surg. 2012;16:486-94.

11. Hicks GL Jr, Brown JW, Calhoon JH, Merrill WH. You never know unless you try. J Thorac Cardiovasc Surg. 2008;136:814-5.

12. Lee JT, Qiu M, Teshome M, Raghavan SS, Tedesco MM, Dalman RL. The utility of endovascular simulation to improve technical performance and stimulate continued interest of preclinical medical students in vascular surgery. J Surg Educ. 2009;66:367-73.

13. Tesche LJ, Feins RH, Dedmon MM, Newton KN, Egan TM, Haithcock BE, et al. Simulation experience enhances medical students' interest in cardiothoracic surgery. Ann Thorac Surg. 2010;90:1967-73; discussion 1973-4.

14. Grover A, Gorman K, Dall TM, Jonas R, Lytle B, Shemin R, et al. Shortage of cardiothoracic surgeons is likely by 2020 . Circulation. 2009;120:488-94. 